\title{
On The Method and Against the Scientific Method, as the Foundation of the Investigative Investigation Theory
}

\author{
Fortunato $S^{*}$ \\ Specialist in Clinic Criminology, President of the degree Course in Linguistic Mediation Sciences, Criminology and Intelligence \\ address at the Criminologia.it Institute of Vibo Valentia, Italy
}

${ }^{*}$ Corresponding author: Fortunato S, Specialist in Clinic Criminology, President of the degree Course in Linguistic Mediation Sciences, Criminology and Intelligence address at the Criminologia.it Institute of Vibo Valentia, Italy, Tel: (+39) 328.1288313, E-mail: fortunatodott@libero.it

Citation: Fortunato S (2018) On The Method and Against the Scientific Method, as the Foundation of the Investigative Investigation Theory. J Forensic Crime 2: 202

Article history: Received: 19 April 2018, Accepted: 18 May 2018, Published: 22 May 2018

Modern Criminology, with reference to the history of science philosophy must anchor itself to epistemology, logic and hermeneutics, to help modern criminal law and criminalism to prosecute the offender for what he does and not for what he is; to construct the theory of investigative investigation by appropriating some methods of the Intelligence, in order to raise the investigative level and reduce the judicial error; it must deal with the 21st century criminal scenarios, dictated by Geopolitics and Geoeconomics.

Today, a coup d'état is no longer (just or only) with missiles and tanks, but with the possession of the mass media and the domain of high finance (Wall Street), which destroys the economy of individual states, neutralizes governments and pushes people to economic despair, with an increase in aggressive crimes, suicides and murders.

Modern Criminology must place the concept of Security, not as a race to rearmament, to transform citizens into gunslingers as in the far west; but intending it as the universal right of man (see human right article 22).

Modern Criminology must include Legal Medicine, Criminal Anthropology, Victimology and, of course, Criminalism. Discover the probable perpetrator of a crime through criminalism; that means, acquiring data and findings to be analyzed in the laboratory is a necessary but insufficient task to avoid the judicial error of an unjust trial. First of all the competence of scientific reasoning is needed.

This is because in the scientific field knowing the causes of a given phenomenon is not in itself sufficient to attest to know what has originated from those causes; the competence of reasoning is needed, since any idea loses its meaning or acquires another respect for the original, if it does not follow principles and does not describe the basic structures and characteristics of reality.

Expert reasoning, therefore, cannot be separated from logic, that is from an argumentation with a complete sense and correspondence rules on the level of coherence and non-contradictory rigor. Given for granted (at least theoretically) that the expert must be expert in something, he must also know how to act in the investigation both as a methodologist (that is, able to build correspondence rules) and as a scientific researcher (applying the correspondence rules).

The criminal process today has become the expertise, but the expertise should know the doubt, because science does not count the right answer, but avoid the wrong one to get away as much as possible from the error.

Karl Popper, in his work "The sources of knowledge and the sources of ignorance", says: "We know nothing. This is the first point. As a result we must be very modest. And this is the second point. That we do not say we know when we do not know, this is the third point [1]. "To this, I add: what is unknown in science is to be silent.

The forensic expertise requires a scientific knowledge that is characterized by the empirical constraint, the logical rigor, the care and the precision with which the operations are treated. The expert bears a tremendous responsibility: the word "condemnation" has a terrible meaning and when justice is wrong, it gives an appeal to anyone who exercises it. His task is to help the judge, honestly and with the gift of doubt, to prevent an innocent from being blamed unjustly or that a culprit can get away with it.

\section{Reference}

1. Popper KR (1969) On the Sources of Knowledge and of Ignorance. Philosophy and Phenomenological Research 23: 292-3. 